\title{
Plant functional group drives the community structure of saprophytic fungi in a grassland biodiversity experiment
}

\author{
Davide Francioli • Sophie Q. van Rijssel • Jasper van Ruijven • \\ Aad J. Termorshuizen • T. E. Anne Cotton • Alex J. Dumbrell • Jos M. Raaijmakers • \\ Alexandra Weigelt • Liesje Mommer (D)
}

Received: 18 October 2019 / Accepted: 4 February 2020 / Published online: 19 February 2020

(C) The Author(s) 2020

\begin{abstract}
Aims Saprophytic fungi are important agents of soil mineralization and carbon cycling. Their community structure is known to be affected by soil conditions such as organic matter and $\mathrm{pH}$. However, the effect of plant species, whose roots provide the litter input into the soil, on the saprophytic fungal community is largely unknown.

Methods We examined the saprophytic fungi in a grassland biodiversity experiment with eight plant species belonging to two functional groups (grasses and forbs),
\end{abstract}

Davide Francioli and Sophie Q. van Rijssel contributed equally to this work.

Responsible Editor: Jeff R. Powell.

Electronic supplementary material The online version of this article (https://doi.org/10.1007/s11104-020-04454-y) contains supplementary material, which is available to authorized users.

D. Francioli $\cdot$ J. van Ruijven $\cdot$ L. Mommer $(\bowtie)$

Plant Ecology and Nature Conservation group, Wageningen University, PO Box 47, 6700AA Wageningen, The Netherlands e-mail: Liesje.Mommer@wur.nl

\section{S. Q. van Rijssel}

Department of Terrestrial Ecology, Netherlands Institute of Ecology (NIOO-KNAW), PO box 50, 6700AB Wageningen,

The Netherlands

\section{A. J. Termorshuizen}

Aad Termorshuizen Consultancy, Kabeljauwallee 11, 6865

BL Doorwerth, The Netherlands combining DNA extraction from plant roots, nextgeneration sequencing and literature research.

Results We found that saprophyte richness increased with plant species richness, but plant functional group richness was the best predictor. Plant functional group was also the main factor driving fungal saprophytic community structure. This effect was correlated with differences in root lignin content and $\mathrm{C}: \mathrm{N}$ ratio between grasses and forbs. In monocultures, root traits and plant functional group type explained $16 \%$ of the variation in

\section{T. E. A. Cotton}

Department of Animal and Plant Sciences, University of Sheffield, Sheffield, South Yorkshire S10 2TN, UK

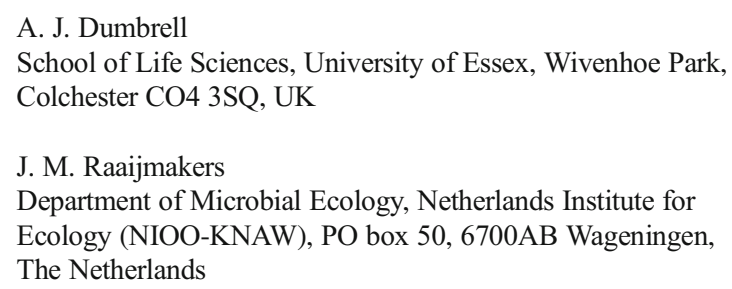

A. Weigelt

Institute of Biology, University of Leipzig, Johannisallee 21, 04103 Leipzig, Germany 
community structure. The saprophyte taxa detected in mixed plant communities were to a large extent subsets of those found in monocultures.

Conclusions Our work shows that the richness and community structure of the root-associated saprophytic fungi can largely be predicted by plant functional groups and their associated root traits. This means that the effects of plant diversity on ecosystem functions such as litter decomposition may also be predictable using information on plant functional groups in grasslands.

Keywords Decomposition - Fungal saprophytes . Grasslands · Plant functional group · Plant species richness $\cdot$ Root traits

\section{Introduction}

Decomposition of plant tissue in terrestrial ecosystems regulates the transfer of carbon and nutrients to the soil (Chapin et al. 2011). The major factors involved in decomposition are soil abiotic conditions (Hättenschwiler et al. 2005; Silver and Miya 2001), plant tissue quality (Chen et al. 2017; Hobbie 1992; Jacoby et al. 2017; Veen et al. 2019) and the decomposer community (Berg 1986). The physical breakdown of plant tissue is done by metazoans, such as earthworms and mites (Eisenhauer et al. 2012), after which the saprophytic fungi perform the initial steps in the decomposition of cellulose, lignin and other complex macromolecules (Berg and McClaugherty 2014a; Gessner et al. 2010). The resulting compounds will be further processed by bacteria (Berg and Laskowski 2005; Kardol and De Long 2018). Hence, saprophytic fungi are generally considered a primary engine of the decomposition process (Maltz et al. 2017; Setälä and McLean 2004).

In grassland ecosystems, the saprophytic community is driven by the quantity of dying and decaying roots, which constitute more than half of the plant biomass (Berg and McClaugherty 2014b; Jackson et al. 1996; Poorter et al. 2012) and are a major organic matter input in soils (Lehmann and Kleber 2015; Silver and Miya 2001). It is well known from biodiversity studies in grasslands that root biomass (Cong et al. 2015; Fargione et al. 2007; Mueller et al. 2013; Oram et al. 2018; Ravenek et al. 2014) and soil organic matter content (Cong et al. 2014; Fornara and Tilman 2008; Lange et al. 2015) increase with plant species richness. This increased quantity of substrate may affect the saprophytic fungal community
(Bray et al. 2012; Cline and Zak 2015). Next to an increased quantity of substrate, the saprophytic community is driven by the quality of the substrate. Plant species vary in their chemical root traits, such as carbon, nitrogen and lignin content (Melillo et al. 1982; Roumet et al. 2016; Schroeder-Georgi et al. 2016; Taylor et al. 1989). For example, Chen et al. (2017) showed that the decomposition rate of standard root litter was significantly lower in plant communities with grasses than without grasses, suggesting that these different plant communities harbour different saprophytic fungal communities. Plant species richness may also affect the root litter quality (De Deyn et al. 2011; Lunghini et al. 2013; Santonja et al. 2017; Schuldt et al. 2018). Highly diverse plant communities may harbour more ecological niches to be occupied by saprotrophic fungi due to an increased diversity of organic substrates entering soils (Grayston et al. 1998; Meier et al. 2008; Waldrop et al. 2006; Zak et al. 2003).

Here we ask what are the best predictors for the saprophytic fungal community: plant species, plant functional groups or plant traits, by investigating the composition of the saprophytic fungi in the tenth year of a grassland biodiversity experiment (van Ruijven and Berendse 2005). Specifically, we studied the saprophytic fungi associated to the plant roots as they may play a pivotal role in dead root decomposition and mineralization, because they are already present on the living roots. The plant communities in the long-term field experiment investigated differed in species richness and composition, ranging from monocultures of two functional groups (grasses and forbs) to mixtures of eight plant species. We hypothesized that: (i) saprophytic fungal community richness will increase with increasing richness of plant functional groups and species, (ii) saprophytic fungal community structure in monocultures will differ between plant functional groups and species, and (iii) saprophytic fungal community structure in mixtures can be predicted from plant functional group and species composition.

\section{Materials and methods}

Experimental design and root collection

The Wageningen Biodiversity Experiment (Wageningen, the Netherlands) was established in March 2000. Briefly, this experiment is a randomised block design (six blocks), with plant species richness (one, two, four and eight species) as the main factor. Plant communities 
comprised the following species: the grasses Agrostis capillaris L., Anthoxanthum odoratum L., Festuca rubra L. and Holcus lanatus L. and forbs Centaurea jacea L., Leucanthemum vulgare Lamk., Plantago lanceolata L. and Rumex acetosa L.. For more information about the experiment, see van Ruijven and Berendse (2005). Here, we used 74 plots affiliated to the Wageningen Biodiversity experiment: six plots with the mixture of all eight plant species (8mix), 22 plots containing grasses and forbs in four-species mixtures: five plots with three grasses and one forb (4mix-3G-1F), 12 plots with two grasses and two forbs (4mix-2G-2F) and five plots with one grass and three forbs (4mix-3F-1G), and 16 plots with two plant species, divided into nine plots with a grass and forb species (2mix-1G-1F), four plots with only grasses $(2 \mathrm{mix}-2 \mathrm{G})$ and four plots with only forbs (2mix2F). Finally, we also included 30 plots with one species (monocultures, four plots per plant per species, except for $H$. lanatus and $R$. acetosa with three plots).

In June 2010, two soil cores (30 mm diameter, $50 \mathrm{~cm}$ deep) were taken (30 cm apart) in each plot. For fungal community analyses in roots, we used two soil layers: 0$5 \mathrm{~cm}$ (shallow layer) and $20-35 \mathrm{~cm}$ (deep layer). The root material collected inevitably was a mixture of dead and living roots. However, due to root washing, albeit careful, the most decayed, slimy parts have been removed. Soil samples were sieved through a $2 \mathrm{~mm}$ mesh. Root and soil samples were kept at $4{ }^{\circ} \mathrm{C}$ for chemical analyses and at $-80{ }^{\circ} \mathrm{C}$ for molecular analyses. The soil samples of the shallow layer collected in all the plots were used to measure total organic $\mathrm{C}$ (TOC) and total $\mathrm{N}(\mathrm{TN})$, soil $\mathrm{pH}$, and soil organic matter (SOM). The root samples from the shallow layer in the monoculture plots were used to measure root $\mathrm{C}$ and $\mathrm{N}$ and lignin content (Table 1). Soil and root chemical analyses were conducted as reported in Cong et al. (2014) and Elle et al. (2019), respectively.

Molecular analyses of the root associated saprophytic fungi

DNA from 80 to $100 \mathrm{mg}$ of plant roots per sample (and thus also DNA of the root-associated fungi) was extracted from the $0-5$ and $20-35 \mathrm{~cm}$ core fractions using the DNeasy Plant mini kit (Qiagen). Fungal DNA amplification was performed using the forward primer ITS1F and reverse primer ITS2 (White et al. 1990) and characterized using 454 GS FLX pyrosequencing by Plant Research International, Wageningen UR, Wageningen, the Netherlands. Reads were analysed using the QIIME pipeline and its associated modules (Caporaso et al. 2010). Subsequent procedures regarding read filtering, chimera removal, OTUs clustering were performed using the bioinformatics pipelines described in Mommer et al. (2018) and available via Dumbrell et al. (2017). Representative sequences of each OTU were assigned taxonomy by comparing each OTU's representative sequence against sequences from the National Center for Biotechnology Information (NCBI) database using the Basic Local Alignment Search Tool (BLAST, Altschul et al. 1990). Fungal OTU accumulation curves were computed using

Table 1 Soil and root properties measured in the shallow layer in the monoculture plots

\begin{tabular}{|c|c|c|c|c|c|c|c|}
\hline \multirow[t]{2}{*}{ Plant community } & \multicolumn{5}{|c|}{ Soil parameters } & \multicolumn{2}{|c|}{ Root parameters } \\
\hline & $\mathrm{pH}$ & $\begin{array}{l}\text { TOC } \\
(\mathrm{g} / \mathrm{kg})\end{array}$ & $\begin{array}{l}\mathrm{TN} \\
(\mathrm{g} / \mathrm{kg})\end{array}$ & $\mathrm{C} / \mathrm{N}$ & $\begin{array}{l}\text { SOM } \\
(\%)\end{array}$ & Root lignin & $\begin{array}{l}\text { Root } \\
\text { C/N }\end{array}$ \\
\hline A. capillaris & $6.2(0.1)$ & $70.0(6.5)$ & $8.2(0.9)$ & $8.6(0.6)$ & $1.8(0.3)$ & $6.2(0.1)^{\mathrm{a}}$ & $57.4(2.7)^{\mathrm{a}}$ \\
\hline A. odoratum & $6.4(0.1)$ & $76.4(3.4)$ & $8.9(0.5)$ & $8.5(0.3)$ & $1.8(0.5)$ & $5.7(0.3)^{\mathrm{ab}}$ & $43.5(0.8)^{\mathrm{b}}$ \\
\hline F. rubra & $6.2(0.1)$ & $71.1(3.2)$ & $7.1(0.2)$ & $10.0(0.5)$ & $1.7(0.1)$ & $6.5(0.3)^{\mathrm{a}}$ & $42.8(0.7)^{\mathrm{b}}$ \\
\hline H. lanatus & $6.1(0.2)$ & $72.4(5.5)$ & $9.2(1.1)$ & $7.9(0.8)$ & $1.6(0.1)$ & $6.8(0.4)^{\mathrm{a}}$ & $37.4(1.6)^{\mathrm{c}}$ \\
\hline C. jacea & $6.3(0.2)$ & $79.7(3.4)$ & $9.6(1.3)$ & $8.7(1.0)$ & $1.8(0.1)$ & $4.1(0.1)^{\mathrm{cd}}$ & $33.2(1.1)^{\mathrm{cde}}$ \\
\hline L. vulgare & $6.3(0.1)$ & $71.5(6.4)$ & $8.5(1.4)$ & $8.8(0.8)$ & $1.6(.03)$ & $4.0(0.3)^{\mathrm{cd}}$ & $34.2(1.6)^{\mathrm{cd}}$ \\
\hline P. lanceolata & $6.3(0.1)$ & $73.2(2.7)$ & $7.9(0.4)$ & $9.2(0.7)$ & $1.7(0.1)$ & $4.7(0.7)^{\mathrm{bc}}$ & $31.1(1.5)^{\mathrm{de}}$ \\
\hline R. acetosa & $6.4(0.1)$ & $69.2(3.2)$ & $7.7(0.7)$ & $9.2(0.8)$ & $1.6(0.1)$ & $3.1(0.6)^{\mathrm{d}}$ & $29.8(0.4)^{\mathrm{e}}$ \\
\hline
\end{tabular}

Values are means and standard error of the means are indicated in parentheses

Abbreviations: TOC total organic carbon, $T N$ total nitrogen, SOM soil organic matter

Different letters denote significant $(P<0.05)$ differences between plant species 
rarefaction and visually inspected. In general, most samples had OTU accumulation curves that were beginning to reach an asymptote and for those that did not, the rates of OTU accumulation were not significantly different from those in other samples, indicating statistical comparisons at lower sequencing intensity were unlikely to be qualitatively different to those conducted with greater sequencing depth. To account for differences in sequencing depths, samples were rarefied to 1000 sequences per sample. All sequences have been submitted to the European Nucleotide Archive (study accession number PRJEB18545). Because we were mainly interested in the fungi involved in the decomposition of root litter, we focused on the ecological guild of saprophytic fungi that were associated to our root samples of mature plants, likely providing a mix of young and older roots. We refer to these saprophytic fungi as Root Associated Saprophytic Fungi (RASF). We have excluded the arbuscular mycorrhizal fungi (AMF) from the analysis since they lack substantial saprophytic capability (Azcón-Aguilar et al. 1999; Hodge 2014) and the primer set employed for the fungal identification in this study has a low resolution for this fungal group. Functional characterisation of the obtained fungal OTUs into saprophytes was performed using a combination of FUNGuild (Nguyen et al. 2016) and complementary literature research (Arnolds and van den Berg 2013; Dighton 2016; Dighton and White 2017; Domsch et al. 2007; Farr and Rossman 2014; Griffith and Roderick 2008). In this study we opted for a pragmatic approach, only considering those fungal taxa with their saprophytic capability as known from literature in August 2019. This means that some fungal endophytes that have only been suggested to have saprophytic potential have not been included in our analyses. Please note that the pathogenic fungal community of this experiment has already been described in another study (Mommer et al. 2018).

\section{Statistical analyses}

In our analyses of the root-associated saprophytic fungal richness and community structure, we follow a two-step approach, in which we first determine the effects of plant species and functional group in the monocultures. In the next step, we use the full dataset to determine the effects of plant species richness, plant functional group richness and plant functional group composition on the saprophytic fungal community structure and richness.
Saprophytic fungal richness

In the monoculture dataset, saprophytic fungal richness was analysed using linear mixed effects models (LME) with either plant species or functional group identity, and depth (nested within plot to account for the fact that the two depths are not independent) as fixed factors, and block as a random factor. In the full dataset, we investigated the effects of plant functional group richness (PFR; the number of different plant functional group within a plant community) and plant species richness (PSR) on saprophytic fungal richness using linear mixed effects models (LME) with block as a random factor, soil depth nested within plot as fixed factor and plant species or functional group richness as a covariate. To identify the most parsimonious model, the Akaike information criterion corrected for small sample sizes (AICc; Burnham and Anderson (2002)) was used. The variance explained (conditional $\mathrm{R}^{2}$ ) by the mixed effect models was calculated by the r.squaredLR function in MuMIn Package (Bartón 2016). All the models were analysed using the lme4 R package (Bates et al. 2015). Lastly, the relationships between the fungal OTU richness and root traits and soil properties were calculated using non-parametric Spearman's rank correlation.

\section{Saprophytic fungal community structure}

The differences in overall community composition between samples were calculated using the Bray-Curtis dissimilarity index after Hellinger transformation (Legendre and Gallagher 2001). Non-metric multidimensional scaling (NMDS) was used to visualize the effects of plant community structure on the saprophytic fungal community. Permutational analysis of variance (PERMANOVA), as implemented in the adonis function from the vegan package (Oksanen et al. 2018), was used to test for differences in saprophytic fungal community composition across factors.

In the monoculture dataset, PERMANOVA was first applied to explore the effects of plant species and soil depth (model 0) on the saprophytic fungal community structure. Furthermore, to assess the extent to which plant functional group captured the differences in the saprophytic fungal community between plant species, we performed an additional PERMANOVA analysis where plant functional group was fitted before species plant species and soil depth in the model (model 1). To assess which OTUs were responsible for the observed 
differences in community structure among the different monocultures, SIMPER (similarity percentage) analysis was applied. To assess the relationships between the environmental variables (soil properties and root chemical traits) and saprophytic fungal community structure in the shallow layer in monoculture plots we used the envfit $\mathrm{R}$ function within the vegan $\mathrm{R}$ package (Oksanen et al. 2018). Furthermore, we performed variance partitioning based on redundancy analysis (RDA) to quantify the contribution of soil and root properties, and plant functional groups to the structure of the saprophytic fungal community in the shallow layer within the monoculture plots. Following Blanchet et al. (2008) we first tested the significance of the global model using all predictors. Variable selection was then done using forward selection implemented with function forward.sel in the R package packfor (Dray et al. 2011) following the recommended stopping rules in Blanchet et al. (2008). Variance partitioning was conducted using the varpart function in the vegan $\mathrm{R}$ package (Oksanen et al. 2018).

In the full dataset, PERMANOVA was employed to explore the effects of plant functional group richness (PFR), plant species richness (PSR) and soil depth on saprophytic fungal community structure. First, we analyzed the effects of PFR and PSR on saprophytic fungal community in separate models together with soil depth. Second, PFR was fitted before PSR and soil depth to assess whether PSR could explain variation that was not captured by PFR. Furthermore, we investigated whether plant fungal group composition affected the saprophytic fungal community structure across the plant species richness gradient. We first assessed whether there was difference in saprophytic fungal community structure between the grass only, forb only and grass-forb communities (mixed communities). We then performed pairwise PERMANOVA tests between all the different functional group combinations examined in this study. Statistical significances were based on 9999 permutations and Bonferronicorrected $P$ values were used when more than two groups were compared. SIMPER (similarity percentage) analysis was employed to assess which OTUs were primarily responsible for the observed differences in community structure among the different plant communities across the plant richness gradient. Voronoi diagrams were made using the treemap package in $\mathrm{R}$. All statistical analyses were carried out using $\mathrm{R}$ version 3.50 (R Core Team 2014).

\section{Results}

Our analyses on 148 root samples from two soil depths resulted in 605,766 high quality sequences representing 988 fungal OTUs of which 355 OTUs were characterized as 'saprophytic' (Table S1). Of the 355 rootassociated saprophytic fungal (RASF) OTUs, 245, 218, 236, and 112 were found in monocultures, 2-, 4-, and 8 - species plots, respectively. Ascomycota was the dominant phylum (216 OTUs, 61\%), followed by Basidiomycota (119 OTUs, 33\%) and Mucoromycota (20 OTUs, 6\%) (Fig. S1). The 355 saprophytic fungal OTUs clustered in 157 fungal genera, most of which were affiliated to the Ascomycota (105). The remaining OTUs were associated with the genera Basidiomycota (49) and Mucoromycota (3). Among the Ascomycota, common saprophytic fungal genera like Pezizella, Lachnum, Tetracladium and Preussia were the most abundant, accounting for 14, 12, 10 and $4 \%$ of the total saprophyte fungal reads, respectively. Coprinellus (15\%) and Cotylidia (3\%) were the dominant Basidiomycota genera, while Mortierella (1\%) was the most abundant genus within Mucoromycota.

Fungal saprophytic richness

In the monoculture plots, RASF richness was significantly higher in the shallow than in the deep layer $\left(\mathrm{F}_{1,29}=16.6, P<0.001\right)$ (Fig. 1a). Plant species identity $\left(\mathrm{F}_{7,29}=1.91 ; P=0.12\right)$ and plant functional group $\left(\mathrm{F}_{1,29}=0.21 ; P=0.65\right)$ did not have an effect on RASF richness. No interaction was found between soil depth and plant species identity $\left(\mathrm{F}_{7,28}=0.69, P=0.67\right)$ nor between soil depth and plant functional group $\left(\mathrm{F}_{1,28}=\right.$ $0.19, P=0.66$ ). In monocultures, RASF richness was not significantly related to any of the soil properties or root traits measured (Table S2).

When analysing all plots (i.e. monocultures and mixtures), RASF richness increased significantly with both plant species richness (Fig. $1 \mathrm{~b} ; \mathrm{F}_{1,68}=5.57, P<0.05$ ) and plant functional group richness (PFR) (Fig. 1c; $\left.\mathrm{F}_{1,68}=10.87, P<0.01\right)$. However, the model with PFR $\left(\mathrm{AICc}=986.64, \mathrm{R}^{2}=0.188\right)$ performed better than the one with PSR ( $\left.\mathrm{AICc}=994.79, \mathrm{R}^{2}=0.153\right)$, suggesting that PFR is a better predictor for RASF richness.

RASF richness was significantly higher in the shallow than in the deep layer (Fig. $1 \mathrm{~b} ; \mathrm{F}_{1,64}=7.12$, $P<0.001)$. No significant interactions were observed 
Fig. 1 Root-associated saprophytic fungal (RASF) richness across the different plant communities investigated in this study. Boxplot representing RASF richness in the shallow and deep soil layers across the a) eight monocultures, b) plant species richness levels and c) plant functional group richness a
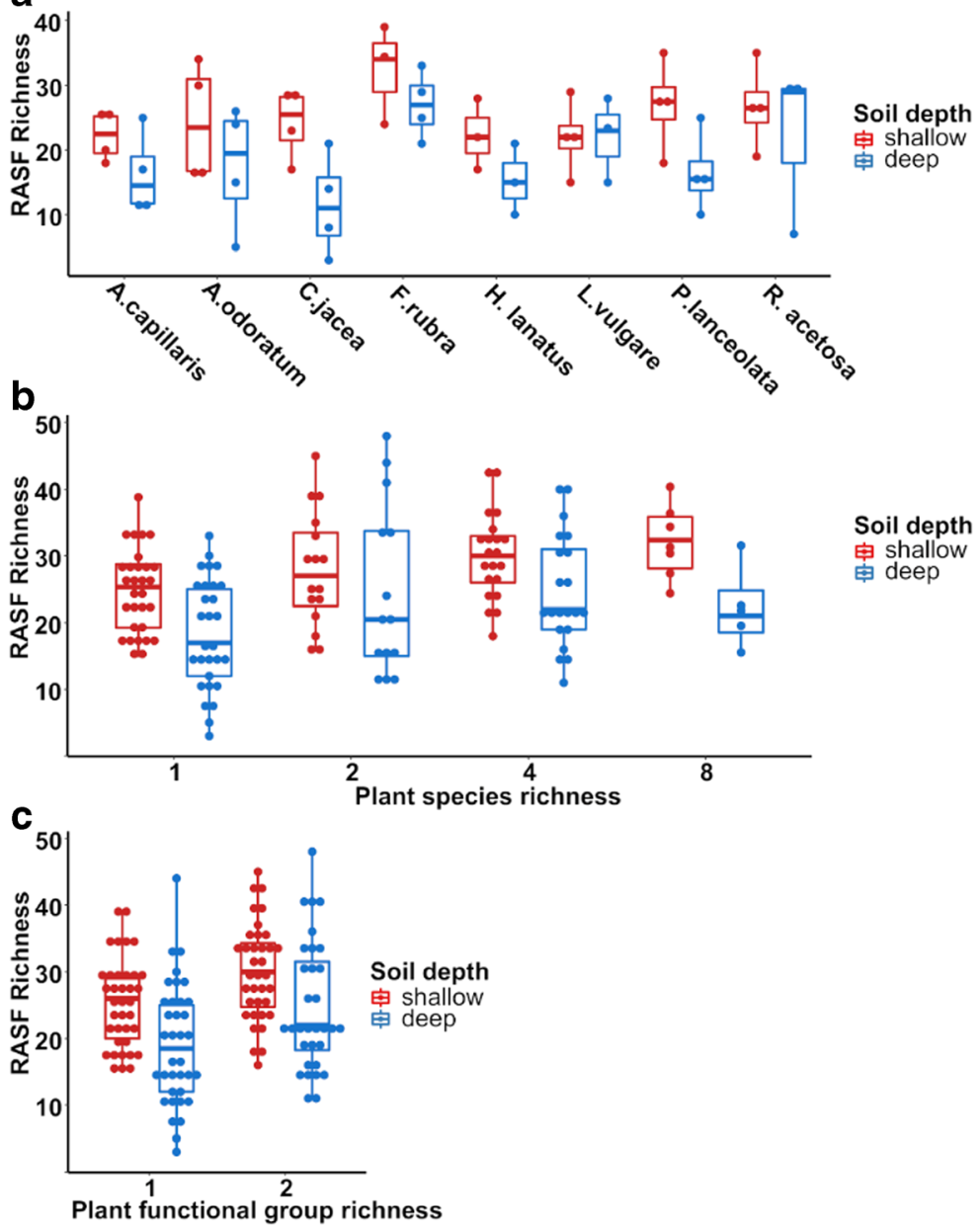

between soil depth and PSR $\left(\mathrm{F}_{1,64}=0.16, P=0.68\right)$ and PFR $\left(\mathrm{F}_{1,64}=0.12, P=0.73\right)$.

Total organic carbon, $\mathrm{C}: \mathrm{N}$ ratio and soil organic matter in the shallow soil layer increased significantly with plant species richness (Table S3) and they were also significantly $(\mathrm{P}<0.05)$ positively correlated with RASF richness (Table S4). However, among the models tested, which included plant species richness or PFR or the soil parameters as fixed factors, the model that included only PFR was the most parsimonious in predicting RASF richness in the shallow layer across the species richness gradient $\left(\mathrm{AICc}=491.52, \mathrm{R}^{2}=0.143\right)$.

Fungal saprophytic communities in monocultures

In the monocultures, plant species had a significant effect on RASF community structure, explaining $32 \%$ of variation (Fig. 2a and Fig. S2; $F_{7,58}=3.43, \mathrm{P}<0.001$ )
(Table S5), while soil depth did not have a significant effect $\left(\mathrm{F}_{1,58}=1.34, P=0.13\right)$ and there was no significant interaction between depth and plant species $\left(\mathrm{F}_{7,58}=0.94, P=0.64\right)$. Our subsequent PERMANOVA analysis revealed a significant effect of plant functional group on RASF community structure (i.e. grasses vs forbs; Fig. 2a and Fig. S2; $F_{1,58}=9.08, P<0.001$ ), capturing $12.1 \%$ of the total variance (Table S5). Hence, functional group captured $38 \%$ of the variance explained by plant species. We did not find a significant interaction between soil depth and plant functional group $\left(\mathrm{F}_{1,58}=1.13, \mathrm{P}=0.31\right)$.

Of the 245 OTUs encountered in the monocultures, 90 were found in at least one grass and one forb (only 9 OTUs were detected in all eight plant species, see Fig. S3), indicating that approximately $40 \%$ of the OTUs is shared among the grasses and forbs. This may suggest that approximately $60 \%$ is either grass or forb specific. 

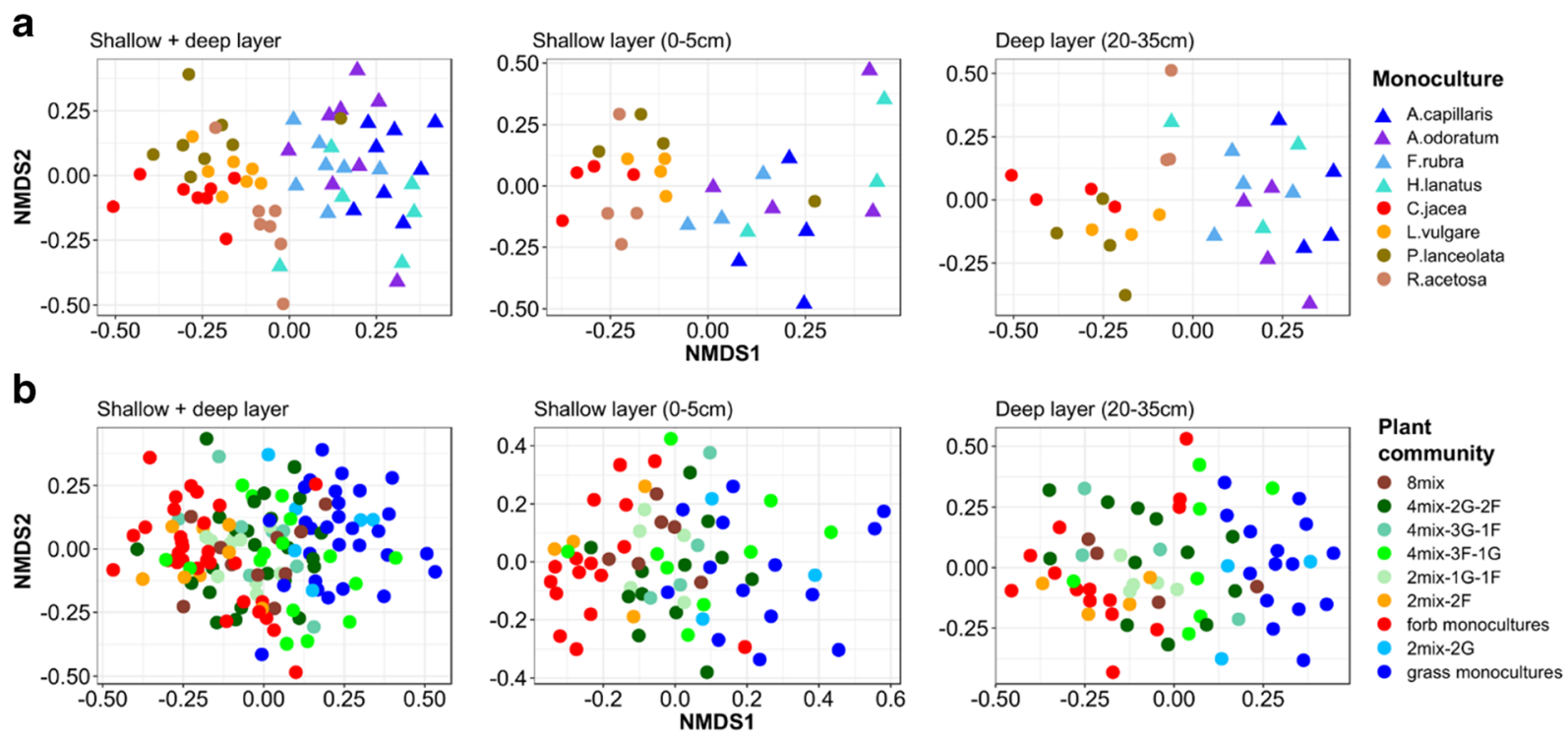

Fig. 2 Root-associated fungal saprophyte (RASF) communities across the plant communities investigated in this study. Nonmetric multidimensional scaling (NMDS) ordinations, based on BrayCurtis distance of RASF communities associated (a) with the eight monocultures and ( b) with all the different plant species richness levels. Results are displayed in combination (left) and separately for the shallow $(0-5 \mathrm{~cm}$, middle) and deep $(20-35 \mathrm{~cm}$, right) soil layers
However, within each plant functional group, we found that the proportion of unique OTUs detected in each plant species ranged from the 17 to the $35 \%$ in the grasses and from 28 to $40 \%$ in the forb monocultures (Fig. S3).

In each monoculture, the seven most abundant OTUs accounted for approximately $60-85 \%$ of the sequence reads, indicating that each monoculture was dominated by a few saprophytic taxa (Fig. 3a). Within a plant functional group, each plant species was dominated by the same OTUs (Fig. 3a), whereas between plant functional group these OTUs were different (Fig. 3a; Fig. S4). The dominant functional group-specific OTUs were further identified as the major contributors to the dissimilarity (66.87\%) in fungal saprophytic community composition between grass and forb monocultures (Table 2). Indeed, the forb monocultures showed high abundances of OTU 4 (Tetracladium furcatum), OTU 6 (Pezizella discreta), OTU 2 (Coprinellus micaceus) and OTU 10 (Coprinellus disseminatus), which were not well represented in the grasses (Table 2). On the contrary, OTU 5 (Lachnum spartinae), OTU 7 (Lachnum virgineum) and OTU 8 (Pezizella chrysostigma) were remarkably more abundant in grass than in forb monocultures (Table 2).

Soil properties did not differ significantly between the eight plant species, but root $\mathrm{C}: \mathrm{N}$ ratio $\left(\mathrm{F}_{1,28}=14.47\right.$,
$P<0.001)$ and root lignin content $\left(\mathrm{F}_{1,28}=48.63, \mathrm{P}<\right.$ 0.001 ) were significantly higher in the grass monocultures compared to the forbs (Table 1; Fig. S5). These two root traits were positively correlated to each other $(\mathrm{r}=0.49, P<0.01)$ and were also significantly $(P<0.05)$ associated to RASF community structure in the shallow soil layer (Table S6). Variance partitioning demonstrated that $16 \%$ of the variation in the RASF community structure in the monocultures was explained by plant functional group and root traits together, with corresponding pure effect of $4 \%$ and $3 \%$, respectively, whereas soil properties had a significant but marginal effect (Fig. 4).

Fungal saprophytic communities across the plant richness gradient

Across the plant species gradient, RASF community structure was significantly different between the two soil depths (Fig. 2b; $F_{1,140}=3.54, \mathrm{P}<0.001$ ) with soil depth explaining $2.5 \%$ of RASF community variance (Table S7). Surprisingly, RASF community structure was only marginally affected by plant species richness (PSR: $\mathrm{F}_{3,140}=1.37, P=0.057$; PSR x depth: $\mathrm{F}_{3,140}=$ $0.91, P=0.77$ ), but we did find a significant difference between plant communities consisting of one and of two plant functional groups (PFR: $\mathrm{F}_{1,140}=2.12, P<0.005$; 
Fig. 3 Most abundant OTUs in the different plant communities investigated in this study. Voronoi diagrams showing the seven most abundant root-associated saprophytic fungal (RASF) OTUs in a) each of the monocultures, and $\mathbf{b}$ ) in the plant communities across the plant species richness levels. Cell size is proportional to the OTUs relative abundance.

Numbers in parenthesis represent the cumulative relative abundance of the seven most abundant RASF OTUs for each plant community
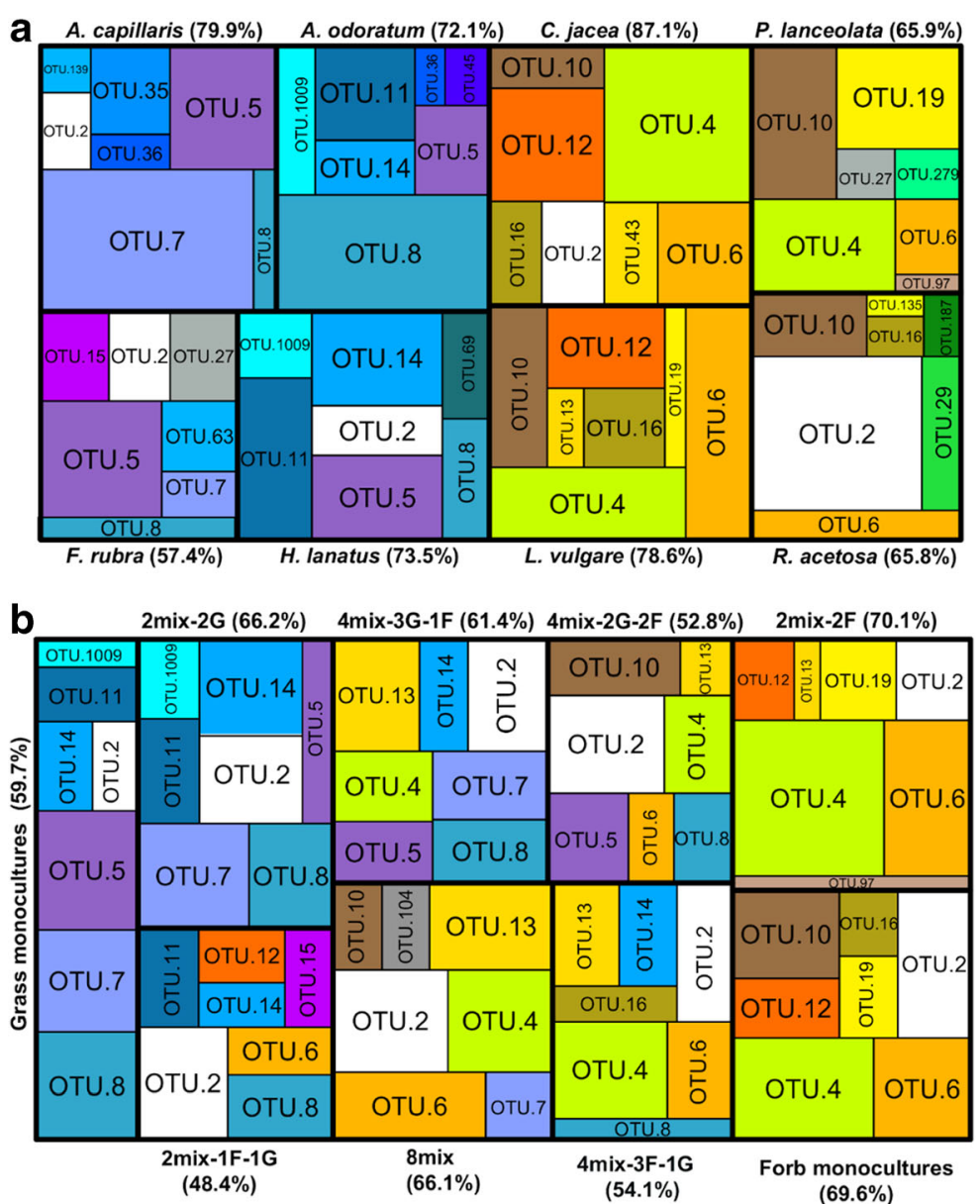

$1.5 \%$ of variance; Table S7). In addition, plant communities consisting of only grasses, only forbs or both differed significantly from each other $\left(\mathrm{F}_{2,140}=7.83, \mathrm{P}\right.$ $<0.001)$. Pairwise comparisons revealed that the biggest differences were found between forb only and grass only communities (Table S8). This effect of plant functional group on the RASF structure is also evident in the NMDS plots (Fig. 2b), which show a clear separation of the grass only and forb only plant communities, with the grassforb communities (mixed communities) clustered in between. RASF community structure did not differ between two, four and eight species mixtures consisting of grasses and forbs. Also, these mixed communities did not differ significantly from forb only or grass only communities (Table S8). We also found no evidence that the proportion of the two plant functional groups within mixtures affected the RASF community structure (Table S8).

In general, we found that the OTUs detected in plots containing mixtures of either two, four or eight plant species were to a large extent a subset of those found in the monoculture plots (Fig. S3). For example, 93 out of the 112 OTUs $(83 \%)$ detected in the 8mix were found in the monoculture samples, while only one OTU was detected only in the 8-mix plots (Fig. S3). Interestingly, RASF communities in the mixed plots were mainly composed and dominated by the most abundant OTUs characterizing the two groups of monocultures (Fig. 3b). SIMPER analysis identified 14 taxa that together accounted for approximatively $66 \%$ of saprophytic community dissimilarity between the plant communities across the plant species richness gradient (Table 3). Most of these OTUs (12 out of 14) were also found as drivers of the community dissimilarity between the grass and forb monocultures (Table 2). However, the other two taxa identified did not contribute to dissimilarity between grasses and forbs in monoculture. Of these, OTU 13 (Cotylidia undulata) was more abundant in 
Table 2 SIMPER analysis results showing the 14 fungal taxa that contributed most to the dissimilarity between grass and forb monocultures

\begin{tabular}{|c|c|c|c|c|c|}
\hline \multirow[t]{2}{*}{ OTU number } & \multirow[t]{2}{*}{ Order } & \multirow[t]{2}{*}{ Taxon } & \multirow[t]{2}{*}{ Variation explained (\%) } & \multicolumn{2}{|c|}{ Monocultures } \\
\hline & & & & Grasses & Forbs \\
\hline OTU.4 & Helotiales & Tetracladium furcatum & 8.72 & 0.21 & 16.40 \\
\hline OTU.2 & Agaricales & Coprinellus micaceus & 8.02 & 4.63 & 12.50 \\
\hline OTU.5 & Helotiales & Lachnum spartinae & 7.12 & 13.30 & 0.31 \\
\hline OTU.8 & Thelebolales & Pezizella chrysostigma & 6.54 & 10.70 & 2.69 \\
\hline OTU.7 & Helotiales & Lachnum virgineum & 5.91 & 11.00 & 0.15 \\
\hline OTU.10 & Agaricales & Coprinellus disseminatus & 5.75 & 0.39 & 10.60 \\
\hline OTU.6 & Thelebolales & Pezizella discreta & 5.71 & 1.46 & 11.30 \\
\hline OTU.12 & Hypocreales & Flagellospora leucorhynchos & 3.92 & 0.20 & 7.33 \\
\hline OTU.11 & Helotiales & Cyathicula sp. & 3.48 & 6.50 & 0.03 \\
\hline OTU.14 & Pleosporales & Preussia africana & 2.89 & 5.42 & 0.09 \\
\hline OTU.19 & Xylariales & Hypoxylon rutilum & 2.79 & 0.05 & 5.23 \\
\hline OTU.16 & Ascomycetes $^{\mathrm{a}}$ & Ypsilina graminea & 2.59 & 0.85 & 4.48 \\
\hline OTU.1009 & Helotiales & Hymenoscyphus scutula & 1.76 & 3.30 & 0.01 \\
\hline OTU.35 & Agaricales & Coprinopsis atramentaria & 1.67 & 3.13 & - \\
\hline
\end{tabular}

Values in the plant community columns (grasses vs forbs) indicate the mean relative abundance of the saprophytic OTUs

a Taxonomy rank $=$ Class

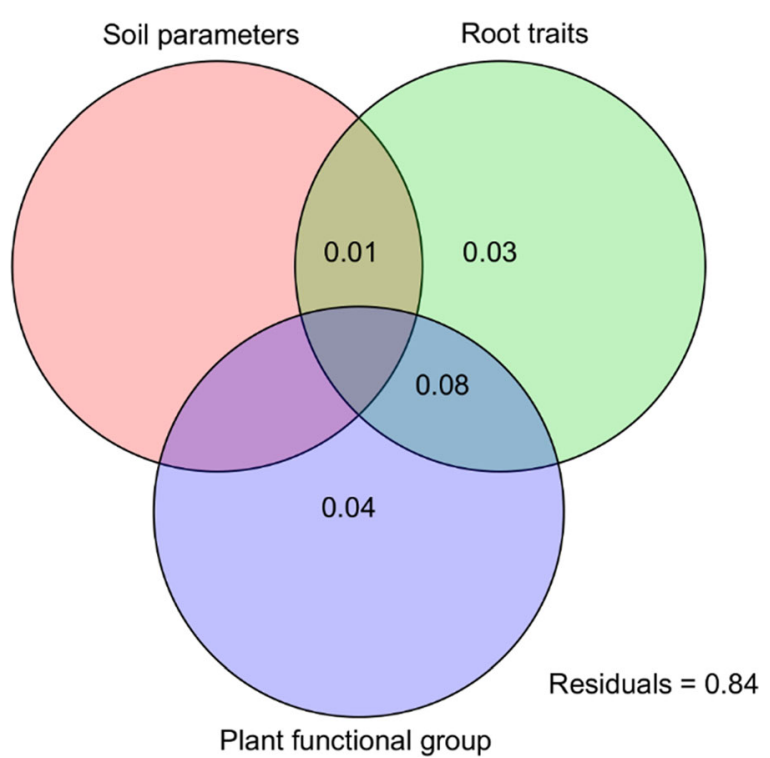

Fig. 4 Variation partitioning analysis, illustrating the effects soil parameters, root traits and plant functional group on the community structure of the root associated saprophytic fungal (RASF) communities found in the shallow layer in the monoculture plots. Each ellipse represents the portion of variation accounted by each factor. Shared variance is represented by the intersecting portions of the ellipses. Values $<0$ are not shown. Unexplained variation (residuals) is reported in the plot mixtures containing grasses and forbs than in plots with just one functional group. The other, OTU 15 (Marasmius tricolor), showed a less clear pattern, being absent in communities containing only forbs or two grasses, and present in the other communities (Table 3).

\section{Discussion}

Root-associated saprophytic fungal (RASF) richness increased with plant species richness in the 10-year old grassland biodiversity experiment, but this effect was largely due to an increase in plant functional group richness with plant species richness. The RASF community structure differed between plant species in monocultures, and primarily so between the two different plant functional groups, as grasses and forbs showed distinct saprophytic fungal communities. This plant functional group effect cascaded into the RASF community composition in plant species mixtures. The clear effect of plant functional group on RASF community composition may be driven by the differences in $\mathrm{C}: \mathrm{N}$ ratio and lignin content of the roots, as these traits are significantly different between the two plant functional groups. 
Table 3 SIMPER analysis results showing the 14 fungal taxa that contributed most to the dissimilarity across the different plant communities investigated in this study

\begin{tabular}{|c|c|c|c|c|c|c|c|c|c|c|c|c|}
\hline $\begin{array}{l}\text { OTU } \\
\text { number }\end{array}$ & Order & Taxon & $\begin{array}{l}\text { Variation } \\
\text { explained } \\
(\%)\end{array}$ & $\begin{array}{l}\text { grass } \\
\text { mono }\end{array}$ & $\begin{array}{l}2 \mathrm{mix}- \\
2 \mathrm{G}\end{array}$ & $\begin{array}{l}4 \operatorname{mix} \\
3 \mathrm{G}- \\
1 \mathrm{~F}\end{array}$ & $\begin{array}{l}2 \mathrm{mix} \\
1 \mathrm{G}- \\
1 \mathrm{~F}\end{array}$ & $\begin{array}{l}4 \operatorname{mix} \\
2 \mathrm{G}- \\
2 \mathrm{~F}\end{array}$ & $8 \operatorname{mix}$ & $\begin{array}{l}4 \operatorname{mix} \\
3 \mathrm{~F}- \\
1 \mathrm{G}\end{array}$ & $\begin{array}{l}2 \mathrm{mix} \\
2 \mathrm{~F}\end{array}$ & $\begin{array}{l}\text { forb } \\
\text { mono }\end{array}$ \\
\hline OTU.2 & Agaricales & $\begin{array}{l}\text { Coprinellus } \\
\text { micaceus }\end{array}$ & 9.84 & 4.63 & 10.60 & 10.50 & 11.70 & 13.40 & 13.80 & 9.06 & 7.06 & 12.50 \\
\hline OTU.4 & Helotiales & $\begin{array}{l}\text { Tetracladium } \\
\text { furcatum }\end{array}$ & 8.14 & 0.21 & 0.15 & 8.21 & 3.89 & 7.85 & 12.50 & 13.00 & 26.60 & 16.40 \\
\hline OTU.8 & Thelebolales & Pezizella discreta & 6.31 & 10.70 & 10.10 & 8.52 & 7.87 & 6.15 & 3.59 & 4.39 & 2.44 & 2.69 \\
\hline OTU.10 & Agaricales & $\begin{array}{l}\text { Coprinellus } \\
\quad \text { disseminatus }\end{array}$ & 5.91 & 0.39 & - & 5.21 & - & 8.73 & 4.97 & - & - & 10.60 \\
\hline OTU.6 & Thelebolales & $\begin{array}{l}\text { Pezizella } \\
\text { chrysostigma }\end{array}$ & 5.74 & 1.46 & 4.05 & 3.57 & 5.86 & 4.77 & 11.90 & 7.40 & 15.80 & 11.30 \\
\hline OTU.5 & Helotiales & Lachnum spartinae & 5.58 & 13.30 & 6.61 & 7.13 & 3.80 & 8.48 & 3.97 & 0.35 & 0.09 & 0.31 \\
\hline OTU.7 & Helotiales & Lachnum virgineum & 4.11 & 11.00 & 13.50 & 9.24 & 2.16 & 1.45 & 5.25 & 0.2 & 0.35 & 0.15 \\
\hline OTU.14 & Pleosporales & Preussia africana & 3.83 & 5.42 & 11.60 & 6.41 & 4.50 & 2.51 & 1.62 & 7.01 & 0.02 & 0.09 \\
\hline OTU.13 & Hymenochaetales & Cotylidia undulata & 3.77 & 1.27 & 0.41 & 11.4 & 3.39 & 3.44 & 12.60 & 8.07 & 2.48 & 1.42 \\
\hline OTU.12 & Helotiales & Cyathicula sp. & 3.12 & 0.20 & - & 0.81 & 5.40 & 0.82 & 0.62 & 2.66 & 5.56 & 7.33 \\
\hline OTU.11 & Hypocreales & $\begin{array}{l}\text { Flagellospora } \\
\text { leucorhynchos }\end{array}$ & 2.88 & 6.50 & 7.58 & 0.53 & 7.07 & 0.04 & 0.12 & 0.06 & 0.06 & 0.03 \\
\hline OTU.19 & Xylariales & Hypoxylon rutilum & 2.81 & 0.05 & - & 0.19 & 1.57 & 2.93 & 3.27 & 1.65 & 7.04 & 5.23 \\
\hline OTU.15 & Agaricales & Marasmius tricolor & 1.85 & 2.02 & - & 0.88 & 5.57 & 3.08 & 0.271 & 0.02 & - & - \\
\hline OTU.1009 & Helotiales & $\begin{array}{l}\text { Hymenoscyphus } \\
\text { scutula }\end{array}$ & 1.71 & 3.35 & 5.77 & 0.50 & 4.16 & 0.243 & 0.01 & 0.03 & 0.22 & 0.01 \\
\hline
\end{tabular}

Values in the plant community column indicate the mean relative abundance of the saprophytic OTUs

Abbreviations: mono monocultures

\section{Drivers of RASF richness}

RASF richness was higher in the shallow soil layer than in the deeper one. This is in line with earlier findings, as the majority of fungal richness in grassland (Jumpponen et al. 2010; Mommer et al. 2018; Zajicek et al. 1986) and agricultural (Oehl et al. 2005) ecosystems is found in the top soil, where root biomass (Oram et al. 2018; Ravenek et al. 2014), soil organic matter content (Fang and Moncrieff 2005; Lange et al. 2015) and microbial activity (Debnath et al. 2015; Taylor et al. 2002) are often highest.

We found positive relationships between aspects of plant biodiversity (i.e. species and functional group richness) and saprophytic fungal richness, and between plant species and soil organic matter in the shallow soil layer. These findings together may suggest that the higher soil organic matter content as a result of plant biodiversity may lead to higher RASF richness (Lunghini et al. 2013; Santonja et al. 2017). Future work has to reveal the relative importance of plant litter inputs and soil organic matter as drivers of fungal richness and community composition in soil (de Vries et al. 2012; Louis et al. 2016; Pellissier et al. 2014; Siles and Margesin 2016), and their links to the diversity in metabolic capacities (i.e., extracellular enzyme synthesis) of saprotrophic fungi (Baldrian 2006; Cline et al. 2018; Grayston et al. 1998; McGuire et al. 2010).

Plant functional group shapes the saprophytic community in the monocultures

Within the monocultures, RASF community was mainly structured by plant species followed by plant functional type. The monoculture communities were dominated by a few plant functional group-specific OTUs. In contrast to RASF richness, RASF community structure did not differ significantly between the two soil layers. This is surprising because other studies exploring total soil or root-associated fungal community found different results (Jumpponen et al. 2010; Mommer et al. 2018; Mujic et al. 2016; Unterseher et al. 2011). Our explanation for a lack of significant differences in RASF community structure between the two soil layers in this 
study is that the dominant saprophytic OTUs characterizing the RASF communities were largely the same in the two soil layers, while nearly all the RASF taxa that were lost with increasing soil depth were rare or low abundant OTUs in the shallow layer.

The grass and forb species were characterized by significantly different root chemical properties, with higher lignin content and $\mathrm{C}: \mathrm{N}$ ratio in grasses than in forbs confirming earlier findings (Chen et al. 2017; Roumet et al. 2016; Schroeder-Georgi et al. 2016). Root $\mathrm{C}: \mathrm{N}$ and lignin content have been identified as plant traits shaping the soil-borne fungal community in grasslands (Cline et al. 2018; Schöps et al. 2018), which corresponds to differences in their decomposition potential (Cline et al. 2018; Melillo et al. 1982; Taylor et al. 1989). Generally, plant litter from grasses decomposes slower than the forbs (Chen et al. 2017; Cornelissen et al. 2017; Cornwell et al. 2008; Griffith and Roderick 2008). Our study confirms these differences between grasses and forbs and their differential impact on RASF. Indeed, we found that the root traits we measured together with plant functional group type explained approximately $16 \%$ of the variation in RASF community structure. However, other root traits that can affect RASF communities, such as root exudate profiles (van Dam and Bouwmeester 2016) or other chemical components as magnesium, potassium and calcium concentration (Schöps et al. 2018) have to be included to capture a greater part of the variation in RASF community structure. Alternatively, plant species may have induced effects on soil macro- and meso- fauna, which can change the structure of plant litter (Carrillo et al. 2011; Eisenhauer et al. 2009) and thus the RASF community, which may have obscured the relationship between RASF community structure and root traits.

Plant functional group composition affects RASF community structure in plant mixtures

The plant mixtures harboured RASF communities that were characterized by the dominant OTUs found in the grass and forb monocultures. Indeed, the most abundant OTUs detected in the monocultures were highly representative for the plant mixtures, and accounted for a large proportion of the total saprophyte fungal reads (ranging from 48.4 to $70.1 \%$ ) in each mixed plant community. The abundance and occurrence of individual saprophytic fungal taxa thus appeared sensitive to particular plant functional groups, probably through an influence of root litter biochemistry and plant community composition (Fornara et al. 2009; Spehn et al. 2000). For example, the relative dominance of grass species increased the abundance of saprotrophic taxa affiliated to the genus Lachnum (OTU 5, Lachnum spartinae and OTU 7, Lachnum virgineum) which have the ability to produce laccase enzymes that are involved in lignin degradation (Lyons et al. 2003), reflecting the more recalcitrant litter chemistry of the grass roots compared to forb roots (Dean et al. 2014). In the grassdominated plots, we also detected a high abundance of the fungal saprophyte Preussia africana (OTU 14). This particular taxon has recently gained considerable attention due to its production of bioactive secondary metabolites, which are typically involved in defence mechanisms against other competing microbes (Bills et al. 2013; Gonzalez-Menendez et al. 2017; Zhang et al. 2012). Contrary to the grasses, forb plant communities showed an increase in saprophytic fungi affiliated to Xylariales and Agaricales orders, as already reported by Cline et al. (2018). Among these forb-enriched saprophytic taxa, Hypoxylon rutilum (OTU 19; Xylariales order, Hypoxylaceae family) represents an ecologically relevant fungus as it is able to produce secondary metabolites that may negatively affect a large spectrum of organisms, including bacteria, fungi, insects and nematodes (Helaly et al. 2018; Hellwig et al. 2005). Overall, our findings clearly indicate that RASF community composition and structure in plant mixtures can largely be predicted by the plant functional groups composing the plant community.

Interestingly, the root-associated pathogenic fungal communities in the same plots as in this study showed a different pattern when comparing mixtures and monocultures (Mommer et al. 2018). More than half of the pathogenic OTUs detected in the monocultures was not found in the mixed plots (Mommer et al. 2018), and pathogen communities in mixtures could not be predicted on the basis of their monocultures. This difference may be due to the fact that fungal pathogens interact with living plants, which can lead to co-evolution of plants and pathogens (Gilbert and Webb 2007; Möller and Stukenbrock 2017). This may have resulted in higher host specificity in pathogens than saprophytes. If host specificity is large, dilution of the plant host with plant species diversity will have more impact on fungal behaviour than when any plant species can be a host (Ampt et al. 2018). The relationship between plant and fungal communities clearly depends on fungal 
ecological guild under study (Alzarhani et al. 2019; Kolarikova et al. 2017).

\section{Conclusions}

We showed that plant species richness can stimulate RASF richness. However, the positive effect of plant species richness on RASF richness was mainly due to combining two plant functional groups (grasses and forbs). Also with regard to the RASF community structure plant functional group was the main driver as grasses and forbs showed clear differences in the fungal taxa dominating their RASF communities. These differences between grasses and forbs were not correlated to their effects on soil properties, but to their differences in root traits, particularly root lignin and $\mathrm{C}: \mathrm{N}$ ratio. In contrast to pathogenic fungi, the plant functional type is a good predictor for saprophytic fungal communities in grasslands.

Acknowledgements We would like to thank our colleagues Hannie de Caluwe, Frans Möller, Annemiek Smit-Tiekstra, Jan Willem van der Paauw, Jan van Walsem and students for their help with root washing and molecular analyses of the fungal communities. L.M. is supported by NWO-VIDI grant 864.14.006. T.E.A.C. received financial support from FEMS.

Author's contribution L.M., T.E.A.C., J.M.R., J.v.R., A.J.D. designed the study; L.M., J.v.R. collected the root samples; T.E.A.C. performed the molecular analyses, D.F., S.Q.R., L.M., T.E.A.C., J.M.R., A.J.T., J.v.R. and A.J.D. analysed the data; D.F., S.Q.R., L.M., J.v.R. wrote the first version of the manuscript. All authors discussed the results, contributed substantially to the drafts and gave final approval for publication. The authors state that there are no conflicts of interests to declare.

Open Access This article is licensed under a Creative Commons Attribution 4.0 International License, which permits use, sharing, adaptation, distribution and reproduction in any medium or format, as long as you give appropriate credit to the original author(s) and the source, provide a link to the Creative Commons licence, and indicate if changes were made. The images or other third party material in this article are included in the article's Creative Commons licence, unless indicated otherwise in a credit line to the material. If material is not included in the article's Creative Commons licence and your intended use is not permitted by statutory regulation or exceeds the permitted use, you will need to obtain permission directly from the copyright holder. To view a copy of this licence, visit http://creativecommons.org/licenses/by/4.0/.

\section{References}

Altschul SF, Gish W, Miller W, Myers EW, Lipman DJ (1990) Basic local alignment search tool. Journal of Molecular Biology 215:403-410. https://doi.org/10.1016/S0022-2836 (05)80360-2

Alzarhani AK, Clark DR, Underwood GJC, Ford H, Cotton TEA, Dumbrell AJ (2019) Are drivers of root-associated fungal community structure context specific? The ISME Journal 13: 1330-1344. https://doi.org/10.1038/s41396-019-0350-y

Ampt EA, van Ruijven J, Raaijmakers JM, Termorshuizen AJ, Mommer L (2018) Linking ecology and plant pathology to unravel the importance of soil-borne fungal pathogens in species-rich grasslands European. Journal of plant pathology. https://doi.org/10.1007/s10658-018-1573-x

Arnolds E, van den Berg A (2013) Beknopte Standaardlijst van Nederlandse Paddenstoelen [Concise checklist of Dutch macrofungi]. Nederlandse Mycologische Vereniging [Dutch Mycological Society],

Azcón-Aguilar C, Bago B, Barea JM (1999) Saprophytic growth of Arbuscular Mycorrhizal Fungi. In: Varma A, Hock B (eds) Mycorrhiza: structure, function. Molecular Biology and Biotechnology. Springer, Berlin Heidelberg, pp 391-408. https://doi.org/10.1007/978-3-662-03779-9 16

Baldrian P (2006) Fungal laccases - occurrence and properties 30: 215-242 https://doi.org/10.1111/j.1574-4976.2005.00010.x

Bartón K (2016) R-package 'MuMIn', model selection and model averaging based on information criteria (AICc and alike). Vienna, Austria

Bates D, Mächler M, Bolker B, Walker S (2015) Fitting linear mixed-effects models using lme4 2015 67:48 doi:10.18637/ jss.v067.i01

Berg B (1986) Nutrient release from litter and humus in coniferous forest soils - a mini review. Scand J For Res 1:359-369

Berg B, Laskowski R (2005) Decomposers: soil microorganisms and animals. In: advances in ecological research, vol 38. Academic press, pp 73-100. doi:https://doi.org/10.1016 /S0065-2504(05)38003-2

Berg B, McClaugherty C (2014a) Decomposer organisms. In: Plant litter: decomposition, humus formation, Carbon Sequestration. Springer Berlin Heidelberg, pp 35-52. doi: https://doi.org/10.1007/978-3-642-38821-7 3

Berg B, McClaugherty C (2014b) Decomposition of fine root and Woody litter. In: Plant litter: decomposition, humus formation, Carbon Sequestration. Springer Berlin Heidelberg, pp 171-187. doi:https://doi.org/10.1007/978-3-642-38821-7_8

Bills GF, Gloer JB, An ZQ (2013) Coprophilous fungi: antibiotic discovery and functions in an underexplored arena of microbial defensive mutualism. Curr Opin Microbiol 16:549-565

Blanchet FG, Legendre P, Borcard D (2008) Forward selection of explanatory variables. Ecology 89:2623-2632. https://doi. org/10.1890/07-0986.1

Bray SR, Kitajima K, Mack MC (2012) Temporal dynamics of microbial communities on decomposing leaf litter of 10 plant species in relation to decomposition rate. Soil Biol Biochem 49:30-37

Burnham KP, Anderson DR (2002) Advanced issues and deeper insights. In: Burnham KP, Anderson DR (eds) Model selection and multimodel inference: a practical information- 
theoretic approach. Springer New York, New York, pp 267351. https://doi.org/10.1007/978-0-387-22456-5_6

Caporaso JG et al (2010) QIIME allows analysis of highthroughput community sequencing data. Nat methods 7 : 335-336. https://doi.org/10.1038/nmeth.f.303

Carrillo Y, Ball BA, Bradford MA, Jordan CF, Molina M (2011) Soil fauna alter the effects of litter composition on nitrogen cycling in a mineral soil. Soil Biology and Biochemistry 43: 1440-1449. https://doi.org/10.1016/j.soilbio.2011.03.011

Chapin F. S, Matson P. A, Vitousek P. M (2011) Carbon inputs to ecosystems. In: Principles of terrestrial ecosystem ecology. Springer New York, New York, pp 123-156. doi:https://doi. org/10.1007/978-1-4419-9504-9_5

Chen $\mathrm{H}$ et al (2017) Plant species richness negatively affects root decomposition in grasslands. J Ecol 105:209-218

Cline LC, Hobbie SE, Madritch MD, Buyarski CR, Tilman D, Cavender-Bares JM (2018) Resource availability underlies the plant-fungal diversity relationship in a grassland ecosystem. Ecology 99:204-216

Cline LC, Zak DR (2015) Soil microbial communities are shaped by plant-driven changes in resource availability during secondary succession. Ecology 96:3374-3385. https://doi. org $/ 10.1890 / 15-0184.1$

Cong WF, Ruijven J, Mommer L, De Deyn GB, Berendse F, Hoffland E (2014) Plant species richness promotes soil carbon and nitrogen stocks in grasslands without legumes. Journal of Ecology 102:1163-1170

Cong WF, van Ruijven J, van der Werf W, De Deyn GB, Mommer L, Berendse F, Hoffland E (2015) Plant species richness leaves a legacy of enhanced root litter-induced decomposition in soil. Soil Biology and Biochemistry 80:341-348

Cornelissen JHC, Grootemaat S, Verheijen LM, Cornwell WK, van Bodegom PM, van der Wal R, Aerts R (2017) Are litter decomposition and fire linked through plant species traits? New Phytol 216:653-669. https://doi.org/10.1111 /nph.14766

Cornwell WK et al (2008) Plant species traits are the predominant control on litter decomposition rates within biomes worldwide. Ecology Letters 11:1065-1071. https://doi.org/10.1111 jj.1461-0248.2008.01219.x

De Deyn GB, Quirk H, Bardgett RD (2011) Plant species richness, identity and productivity differentially influence key groups of microbes in grassland soils of contrasting fertility. Biol Letters 7:75-78

de Vries FT, Manning P, Tallowin JRB, Mortimer SR, Pilgrim ES, Harrison KA, Hobbs PJ, Quirk H, Shipley B, Cornelissen JHC, Kattge J, Bardgett RD (2012) Abiotic drivers and plant traits explain landscape-scale patterns in soil microbial communities. Ecol Lett 15:1230-1239

Dean SL, Farrer EC, Taylor DL, Porras-Alfaro A, Suding KN, Sinsabaugh RL (2014) Nitrogen deposition alters plantfungal relationships: linking belowground dynamics to aboveground vegetation change. Mol Ecol 23:1364-1378. https://doi.org/10.1111/mec.12541

Debnath S, Patra AK, Ahmed N, Kumar S, Dwivedi BS (2015) Assessment of microbial biomass and enzyme activities in soil under temperate fruit crops in north western himalayan region. Journal of soil science and plant nutrition 15:848-866

Dighton J (2016) Fungi in ecosystem processes. Mycology, second edition edn. CRC press, Boca Raton
Dighton J, White J (2017) The fungal community: its organization and role in the ecosystem, fourth edition. Mycology, fourth edition edn. CRC press, Boca Raton

Domsch K, Gams W, Anderson T (2007) Compendium of soil fungi, Second edition. 2nd edn edn. IHW Verlag, Eching

Dray S, Legendre P, Blanchet G (2011) Packfor: forward selection with permutation $\mathrm{R}$ package version $0.0-8 / \mathrm{r} 100$ edn.,

Dumbrell AJ, Ferguson RMW, Clark DR (2017) Microbial community analysis by single-amplicon high-throughput next generation sequencing: data analysis - from raw output to ecology. In: McGenity TJ, Timmis KN, Nogales B (eds) Hydrocarbon and lipid microbiology protocols: microbial quantitation. Community Profiling and Array Approaches. Springer, Berlin Heidelberg, pp 155-206. https://doi. org/10.1007/8623_2016_228

Eisenhauer N, Milcu A, Nitschke N, Sabais AC, Scherber C, Scheu S (2009) Earthworm and belowground competition effects on plant productivity in a plant diversity gradient. Oecologia 161:291-301. https://doi.org/10.1007/s00442009-1374-1

Eisenhauer N, Reich PB, Isbell F (2012) Decomposer diversity and identity influence plant diversity effects on ecosystem functioning. Ecology 93:2227-2240. https://doi.org/10.1890 /11-2266.1

Elle O, Richter R, Vohland M, Weigelt A (2019) Fine root lignin content is well predictable with near-infrared spectroscopy Scientific Reports

Fang C, Moncrieff JB (2005) The variation of soil microbial respiration with depth in relation to soil carbon composition. Plant and Soil 268:243-253

Fargione J et al (2007) From selection to complementarity: shifts in the causes of biodiversity-productivity relationships in a long-term biodiversity experiment. Proceedings biological sciences 274:871-876. https://doi.org/10.1098 /rspb.2006.0351

Farr D, Rossman A (2014) Fungal databases, systematic mycology and microbiology laboratory. ARS, USDA

Fornara DA, Tilman D (2008) Plant functional composition influences rates of soil carbon and nitrogen accumulation. Journal of Ecology 96:314-322. https://doi.org/10.1111/j.13652745.2007.01345.x

Fornara DA, Tilman D, Hobbie SE (2009) Linkages between plant functional composition, fine root processes and potential soil $\mathrm{N}$ mineralization rates. Journal of ecology 97:48-56. https://doi.org/10.1111/j.1365-2745.2008.01453.x

Gessner MO, Swan CM, Dang CK, McKie BG, Bardgett RD, Wall DH, Hättenschwiler S (2010) Diversity meets decomposition. Trends in Ecology \& Evolution 25:372-380. https://doi.org/10.1016/j.tree.2010.01.010

Gilbert GS, Webb CO (2007) Phylogenetic signal in plant pathogen-host range. Proceedings of the National Academy of Sciences 104:4979-4983. https://doi.org/10.1073 /pnas.0607968104

Gonzalez-Menendez V et al (2017) Biodiversity and chemotaxonomy of Preussia isolates from the Iberian Peninsula. Mycol Prog 16:713-728

Grayston SJ, Wang S, Campbell CD, Edwards AC (1998) Selective influence of plant species on microbial diversity in the rhizosphere. Soil Biology and Biochemistry 30:369378. https://doi.org/10.1016/S0038-0717(97)00124-7 
Griffith G. W, Roderick K (2008) Saprotrophic basidiomycetes in grasslands: distribution and function. In: Boddy L, Frankland JC, van west P (eds) British mycological society Symposia series, vol 28. Academic press, pp 277-299. doi:https://doi. org/10.1016/S0275-0287(08)80017-3

Hättenschwiler S, Tiunov A. V, Scheu S (2005) Biodiversity and litter decomposition in terrestrial ecosystems annual review of ecology, Evolution, and Systematics:191-218

Helaly SE, Thongbai B, Stadler M (2018) Diversity of biologically active secondary metabolites from endophytic and saprotrophic fungi of the ascomycete order Xylariales. Nat Prod Rep 35:992-1014

Hellwig V, Ju Y-M, Rogers JD, Fournier J, Stadler M (2005) Hypomiltin, a novel azaphilone from Hypoxylon hypomiltum, and chemotypes in Hypoxylon sect. Mycol Prog 4:39-54. https://doi.org/10.1007/s11557-006-0108-6

Hobbie SE (1992) Effects of plant species on nutrient cycling. trends in ecology \& evolution 7:336-339

Hodge A (2014) Chapter two - interactions between Arbuscular Mycorrhizal Fungi and organic material substrates. In: Sariaslani S, Gadd GM (eds) advances in applied microbiology, vol 89. Academic press, pp 47-99. doi:https://doi. org/10.1016/B978-0-12-800259-9.00002-0

Jackson RB, Canadell J, Ehleringer JR, Mooney HA, Sala OE, Schulze ED (1996) A global analysis of root distributions for terrestrial biomes. Oecologia 108:389-411. https://doi. org $/ 10.1007 / \mathrm{bf00333714}$

Jacoby R, Peukert M, Succurro A, Koprivova A, Kopriva S (2017) The Role of Soil Microorganisms in Plant Mineral Nutrition-Current Knowledge and Future Directions. Frontiers in Plant Science 8:1617. https://doi.org/10.3389 /fpls.2017.01617

Jumpponen A, Jones KL, Blair J (2010) Vertical distribution of fungal communities in tallgrass prairie soil. Mycologia 102: 1027-1041

Kardol P, De Long J (2018) How anthropogenic shifts in plant community composition alter soil food webs [version 1 ; referees: 2 approved] F1000Research 7 doi:https://doi. org/10.12688/f1000research.13008.1

Kolarikova Z, Kohout P, Kruger C, Janouskova M, Mrnka L, Rydlova J (2017) Root-associated fungal communities along a primary succession on a mine spoil: Distinct ecological guilds assemble differently. Soil Biol Biochem 113:143-152

Lange $M$ et al. (2015) Plant diversity increases soil microbial activity and soil carbon storage Nature communications 6

Legendre P, Gallagher ED (2001) Ecologically meaningful transformations for ordination of species data. Oecologia 129: 271-280. https://doi.org/10.1007/s004420100716

Lehmann J, Kleber M (2015) The contentious nature of soil organic matter. Nature 528:60-68. https://doi.org/10.1038 /nature 16069

Louis BP, Maron PA, Menasseri-Aubry S, Sarr A, Lévêque J, Mathieu O, Jolivet C, Leterme P, Viaud V (2016) Microbial Diversity Indexes Can Explain Soil Carbon Dynamics as a Function of Carbon Source. Plos One 11:e0161251. https://doi.org/10.1371/journal.pone.0161251

Lunghini D, Granito VM, Di Lonardo DP, Maggi O, Persiani AM (2013) Fungal diversity of saprotrophic litter fungi in a Mediterranean maquis environment. Mycologia 105:14991515
Lyons JI, Newell SY, Buchan A, Moran MA (2003) Diversity of ascomycete laccase gene sequences in a southeastern US salt marsh. Microbial Ecology 45:270-281. https://doi. org/10.1007/s00248-002-1055-7

Maltz MR, Treseder KK, McGuire KL (2017) Links between plant and fungal diversity in habitat fragments of coastal shrubland. Plos One 12:e0184991. https://doi.org/10.1371/journal. pone. 0184991

McGuire KL, Bent E, Borneman J, Majumder A, Allison SD, Treseder KK (2010) Functional diversity in resource use by fungi. Ecology 91:2324-2332. https://doi.org/10.1890/090654.1

Meier CL, Suding KN, Bowman WD (2008) Carbon flux from plants to soil: roots are a below-ground source of phenolic secondary compounds in an alpine. Ecosystem 96:421-430. https://doi.org/10.1111/j.1365-2745.2008.01356.x

Melillo JM, Aber JD, Muratore JF (1982) Nitrogen and Lignin Control of Hardwood Leaf Litter Decomposition Dynamics. Ecology 63:621-626. https://doi.org/10.2307/1936780

Möller M, Stukenbrock EH (2017) Evolution and genome architecture in fungal plant pathogens. Nature Reviews Microbiology 15:756-771. https://doi.org/10.1038 /nrmicro.2017.76

Mommer L, Cotton TEA, Raaijmakers JM, Termorshuizen AJ, van Ruijven J, Hendriks M, van Rijssel S, van de Mortel J, van der Paauw J, Schijlen EGWM, Smit-Tiekstra AE, Berendse F, de Kroon H, Dumbrell AJ (2018) Lost in diversity: the interactions between soil-borne fungi, biodiversity and plant productivity. New Phytol 218:542-553

Mueller KE, Tilman D, Fornara DA, Hobbie SE (2013) Root depth distribution and the diversity-productivity relationship in a long-term grassland experiment. Ecology 94:787-793. https://doi.org/10.1890/12-1399.1

Mujic AB, Durall DM, Spatafora JW, Kennedy PG (2016) Competitive avoidance not edaphic specialization drives vertical niche partitioning among sister species of ectomycorrhizal fungi. New Phytologist 209:1174-1183. https://doi.org/10.1111/nph.13677

Nguyen NH et al (2016) FUNGuild: an open annotation tool for parsing fungal community datasets by ecological guild. Fungal Ecology 20:241-248. https://doi.org/10.1016/j. funeco.2015.06.006

Oehl F, Sieverding E, Ineichen K, Ris EA, Boller T, Wiemken A (2005) Community structure of arbuscular mycorrhizal fungi at different soil depths in extensively and intensively managed agroecosystems. New Phytologist 165:273-283

Oksanen J et al. (2018) vegan: Community Ecology Package. , R package version 2.5-2. edn.,

Oram NJ et al (2018) Below-ground complementarity effects in a grassland biodiversity experiment are related to deep-rooting species. Journal of Ecology 106:265-277. https://doi. org/10.1111/1365-2745.12877

Pellissier L et al (2014) Soil fungal communities of grasslands are environmentally structured at a regional scale in the Alps. Mol Ecol 23:4274-4290

Poorter H, Niklas KJ, Reich PB, Oleksyn J, Poot P, Mommer L (2012) Biomass allocation to leaves, stems and roots: metaanalyses of interspecific variation and environmental control. New Phytol 193:30-50

R Core Team (2014) R: a language and environment for statistical computing. R Foundation for Statistical Computing, Vienna 
Ravenek JM et al (2014) Long-term study of root biomass in a biodiversity experiment reveals shifts in diversity effects over time. Oikos 123:1528-1536

Roumet $\mathrm{C}$ et al (2016) Root structure-function relationships in 74 species: evidence of a root economics spectrum related to carbon economy. New Phytol 210:815-826. https://doi. org/10.1111/nph.13828

Santonja M et al (2017) Plant litter diversity increases microbial abundance, fungal diversity, and carbon and nitrogen cycling in a Mediterranean shrubland. Soil Biology and Biochemistry 111:124-134. https://doi.org/10.1016/j. soilbio.2017.04.006

Schöps R et al (2018) Land-Use Intensity Rather Than Plant Functional Identity Shapes Bacterial and Fungal Rhizosphere Communities. Front Microbiol:9. https://doi. org/10.3389/fmicb.2018.02711

Schroeder-Georgi T, Wirth C, Nadrowski K, Meyer ST, Mommer L, Weigelt A (2016) From pots to plots: hierarchical traitbased prediction of plant performance in a Mesic grassland. Journal of Ecology 104:206-218. https://doi.org/10.1111 /1365-2745.12489

Schuldt A et al. (2018) Biodiversity across trophic levels drives multifunctionality in highly diverse forests Nature Communications 9

Setälä H, M. A ML (2004) Decomposition rate of organic substrates in relation to the species diversity of soil saprophytic fungi. Oecologia 139:98-107. https://doi.org/10.1007 /s00442-003-1478-y

Siles JA, Margesin R (2016) Abundance and diversity of bacterial, Archaeal, and fungal communities along an altitudinal gradient in Alpine Forest soils: what are the driving factors? Microb Ecol 72:207-220. https://doi.org/10.1007/s00248016-0748-2

Silver WL, Miya RK (2001) Global patterns in root decomposition: comparisons of climate and litter quality effects. Oecologia 129:407-419

Spehn EM, Joshi J, Schmid B, Alphei J, Körner C (2000) Plant diversity effects on soil heterotrophic activity in experimental grassland ecosystems. Plant and Soil 224:217-230. https://doi.org/10.1023/A:1004891807664

Taylor BR, Parkinson D, Parsons WFJ (1989) Nitrogen and Lignin Content as Predictors of Litter Decay Rates: A Microcosm Test. Ecology 70:97-104. https://doi.org/10.2307/1938416

Taylor JP, Wilson B, Mills MS, Burns RG (2002) Comparison of microbial numbers and enzymatic activities in surface soils and subsoils using various techniques. Soil Biology and Biochemistry 34:387-401. https://doi.org/10.1016/S00380717(01)00199-7

Unterseher M, Jumpponen A, Opik M, Tedersoo L, Moora M, Dormann CF, Schnittler M (2011) Species abundance distributions and richness estimations in fungal metagenomicslessons learned from community ecology. Mol Ecol 20:275285. https://doi.org/10.1111/j.1365-294X.2010.04948.x

van Dam NM, Bouwmeester HJ (2016) Metabolomics in the Rhizosphere: Tapping into Belowground Chemical Communication. Trends in Plant Science 21:256-265. https://doi.org/10.1016/j.tplants.2016.01.008

van Ruijven J, Berendse F (2005) Diversity-productivity relationships: initial effects, long-term patterns, and underlying mechanisms proceedings of the National Academy of Sciences of the United States of America 102:695-700 doi: https://doi.org/10.1073/pnas.0407524102

Veen CGF, Snoek BL, Bakx-Schotman T, Wardle DA, van der Putten WH (2019) Relationships between fungal community composition in decomposing leaf litter and home-field advantage effects functional. Ecology. https://doi.org/10.1111 /1365-2435.13351

Waldrop MP, Zak DR, Blackwood CB, Curtis CD, Tilman D (2006) Resource availability controls fungal diversity across a plant diversity gradient. Ecology Letters 9:1127-1135

White T. M, Bruns T, Lee S, Taylor J (1990) Amplification and direct sequencing of fungal ribosomal RNA for phylogenetics. In: PCR protocols: a guide to methods and applications. Academic, San Diego, CA, pp 315-321

Zajicek JM, Hetrick BAD, Owensby CE (1986) The Influence of Soil Depth on Mycorrhizal Colonization of Forbs in the Tallgrass Prairie. Mycologia 78:316-320

Zak D. R, Holmes W. E, White D. C, Peacock A. D, Tilman D (2003) Plant diversity, soil microbial communities, and ecosystem function: are there any links? 84:2042-2050 doi: https://doi.org/10.1890/02-0433

Zhang F, Li L, Niu SB, Si YK, Guo LD, Jiang XJ, Che YS (2012) A Thiopyranchromenone and other Chromone derivatives from an Endolichenic fungus. Preussia africana J Nat Prod 75:230-237

Publisher's note Springer Nature remains neutral with regard to jurisdictional claims in published maps and institutional affiliations. 